\title{
Theorie und Soziologie der politischen Parteien im deutschen Vormärz 1815-1848
}

PHILIPP ERBENTRAUT

Theorie und Soziologie der politischen Parteien im deutschen Vormärz $1815-1848$

\section{Mohr Siebeck}

2016. XII, 391 Seiten.

ISBN 978-3-16-154486-6

DOI 10.1628/978-3-16-154486-6

eBook PDF 69,00€

ISBN 978-3-16-154485-9

fadengeheftete Broschur 69,00€
Gab es tatsächlich einen generellen Anti-Parteien-Affekt im deutschen politischen Denken des 19. Jahrhunderts? Philipp Erbentraut argumentiert gegen diesen Mythos und zeigt, dass es im Gegenteil bereits im Vormärz (1815-1848) eine positive und elaborierte Theorie und Soziologie der politischen Parteien gegeben hat, der ein modernes Parteienverständnis zugrunde lag. Er hinterfragt, inwiefern diese Positionen avanciertes politikwissenschaftliches Denken vorwegnahmen und sogar heutige Ansätze der Parteienforschung befruchten könnten. Aktuelle Krisensymptome der Parteiendemokratie wie Politikverdrossenheit, Wahlmüdigkeit oder Mitgliederschwund führt er auf ihre erstmalige theoretische Durchdringung vor beinahe 200 Jahren zurück. Durch die Auswertung von mehr als 250 staatsphilosophischen Quellen kann er belegen, dass quer durch alle politischen Lager dabei freundliche, offen parteienbefürwortende Stellungnahmen überwiegen.

Diese Arbeit wurde mit dem Wilhelm-Liebknecht-Preis der Universitätsstadt Gießen 2017 und dem Dissertationspreis der Deutschen Vereinigung für Politikwissenschaft (DVPW) 2017 ausgezeichnet.

Philipp Erbentraut Geboren 1982; Studium der Politik und Geschichte; 2015 Promotion; seit 2015 Akademischer Rat für Politische Soziologie und Staatstheorie an der Goethe-Universität Frankfurt am Main.

Jetzt bestellen:

https://mohrsiebeck.com/buch/theorie-und-soziologie-der-politischen-parteien-im-deutschen-vormaerz-1815-1848-

9783161544866?no_cache=1

order@mohrsiebeck.com

Telefon: +49 (0)7071-923-17

Telefax: $+49(0) 7071-51104$ 